\title{
Participación del sistema IGF en la patogenia de la enfermedad quística ovárica bovina
}

\author{
Rodriguez $\mathrm{FM}^{1^{*}}$, Salvetti $\mathrm{NR}^{1,2}$, Ortega $\mathrm{HH}^{1,2}$, Rey $\mathrm{F}^{1,2}$
}

1 Laboratorio de Biología Celular y Molecular Aplicada, Instituto de Ciencias Veterinarias del Litoral, Universidad Nacional del Litoral - Consejo Nacional de Investigaciones Científicas y Técnicas (UNL-CONICET), Argentina

2 Departamento de Ciencias Morfológicas, Facultad de Ciencias Veterinarias, Universidad Nacional del Litoral, Santa $\mathrm{Fe}$, Argentina.

* Correspondencia: Laboratorio de Biología Celular y Molecular Aplicada. ICIVET Litoral (UNL-CONICET).Facultad de Ciencias Veterinarias Kreder 2805. (3080) Esperanza, provincia de Santa Fe. Email:

fernandamrodriguez@hotmail.com.

Recibido: 24 Febrero 2016. Aceptado: 21 Abril 2016. Disponible en línea: 22 Abril 2016.

Editor: P. Beldomenico

\begin{abstract}
RESUMEN. La enfermedad quística ovárica (COD) es una de las principales causas de falla reproductiva y de infertilidad, y constituye uno de los de los trastornos reproductivos más frecuentes en vacas lecheras de alta producción. El desarrollo de esta enfermedad está asociado a un desequilibrio en el eje hipotalámico-hipofisario-gonadal en el cual factores endocrinos, entre ellos el sistema de factores de crecimiento análogos a insulina (IGF), participan en el desarrollo folicular, diferenciación celular y la secreción de hormonas ováricas. Considerando al sistema IGF como un importante regulador del crecimiento y funcionalidad folicular, evaluamos la participación de componentes del sistema IGF en el desarrollo de la COD. Las alteraciones en diferentes componentes del sistema IGF que podrían afectar al normal funcionamiento del ovario participando en el desarrollo de la COD en bovinos.
\end{abstract}

SUMMARY. Participation of the IGF system in the pathogenesis of bovine cystic ovarian disease. Cystic ovarian disease (COD) is one of the most frequent reproductive disorders in dairy cows. Their development is associated with an imbalance in the hypothalamushypophyseal-gonadal axis in which endocrine factors, including insulin like growth factor (IGF) system, are involved in follicular development, cell differentiation and secretion ovarian hormones. Considering that the IGF system is an important regulator of the follicular growth and functionality, we have evaluated the involvement of members of the IGF system in the COD development. Alterations in different components of the IGF system could modify the normal ovarian function and participate in the development of the COD in cattle.

Palabras clave: sistema de factores de crecimiento análogos a insulina, enfermedad quística ovárica, bovinos

Key words: insulin like growth factor system, cystic ovarian disease, cow.

\section{Introducción}

El desarrollo folicular está regulado principalmente por la hormona foliculoestimulante (FSH) y la hormona luteinizante (LH), sin embargo existen evidencias que indican que los factores de crecimiento como el sistema de factores de crecimiento análogos a insulina (IGF), actúan en sinergia con las gonadotropinas y pueden actuar localmente en las células del folículo promoviendo o atenuando la diferenciación celular (Giudice, 1992; Spicer y Echternkamp, 1995; Monget, 1996; Adashi, 1998; Spicer et al., 2000; Davidson et al., 2002; Brogan et al., 2010).

A nivel intraovárico los IGFs constituyen importantes reguladores del crecimiento, desarrollo y selección folicular, atresia, diferenciación celular o esteroidogéne- sis; por lo que una falla en la regulación de dicho sistema puede ocasionar alteraciones en el ciclo estral normal y conducir a importantes problemas reproductivos (Ortega et al., 2008; Rey et al., 2010; Rodríguez et al., 2011; 2013; 2015). Una importante causa de infertilidad en el bovino es la enfermedad quística ovárica (COD). Esta enfermedad se caracteriza por el desarrollo de un folículo con diámetro superior al ovulatorio, que falla en ovular y persiste en el tiempo ocasionando trastornos en la funcionalidad ovárica (Vanholder et al., 2006). La COD constituye uno de los trastornos reproductivos más frecuentes en vacas lecheras (Vanholder y col., 2006). Los quistes ováricos ocasionan importantes pérdidas económicas en la producción, dado que provocan una prolongación de los intervalos parto-primer celo, parto-concepción y parto-parto (Silvia y col., 2002). Debido a esto, se ge- 
neran incrementos en los costos veterinarios y aumentos de la tasa de rechazo (Peter, 2004; Vanholder y col., 2006; Rizzo y col., 2011) causando altas pérdidas económicas por lactancia (Johnston y col., 1997; Silvia y col., 2002). Se ha descripto en diferentes tipos de rodeos, que la incidencia de esta enfermedad puede variar entre un 2,7 a un $19 \%$ de las vacas durante el período posparto, causando pérdidas significativas a la producción pecuaria (Vanholder et al., 2006, Cattaneo et al., 2014).

\section{Descripción del sistema IGF}

El sistema IGF está compuesto por dos ligandos, IGF1 y 2 , que activan una cascada de señalización intracelular y proteínas de unión (IGFBPs), que regulan la biodisponibilidad de los ligandos prolongando su vida media y pueden inhibir o favorecer la acción de los IGFs en las células blanco dependiendo de su unión (Giudice, 1992; Rajaram et al., 1997; Monget et al., 2002; Cantero et al., 2007). Además, este sistema está compuesto por receptores que se unen con diferente afinidad a cada ligando (IGFR1 y 2) provocando la señalización interna, y proteasas específicas que escinden a las IGFBPs disminuyendo su afinidad por el ligando, permitiendo que éstos queden disponibles para unirse al receptor (Giudice, 1992; Jones y Clemmons, 1995; Conover et al., 2001, Monget et al., 2002; Brogan et al., 2010).

Los IGF1 y 2 son péptidos estructuralmente relacionados a la proinsulina (Giudice, 1992; Cantero et al., 2007) que participan en la proliferación, diferenciación y apoptosis celular. El IGF1 ejerce acciones anabólicas en el metabolismo de carbohidratos y proteínas, en cambio el IGF2 predomina durante el desarrollo prenatal y, después del nacimiento su función es gradualmente reemplazada por el IGF1. Si bien la concentración de IGF2 en circulación y en líquido folicular (LF) es elevada, el IGF1 sería el principal inductor de las respuestas (Cantero et al., 2007).

La principal fuente de IGF sistémico es el hígado, y la hormona de crecimiento $(\mathrm{GH})$ es la principal reguladora de la expresión y secreción hepática de IGF (Etherton y Bauman, 1998; Cantero et al., 2007). Ambos ligandos son capaces de ejercer acciones tanto endocrinas como paracrinas (Giudice, 1992; Cantero et al., 2007). Además, pueden actuar solos o en sinergia con las gonadotropinas, siendo la estimulación de la esteroidogénesis una de sus principales funciones (Giudice, 1992; Spicer y Echternkamp, 1995; Monget et al., 1996; Adashi, 1998; Brogan et al., 2010). En bovinos, la principal fuente de IGF1 en LF es la circulación y existen evidencias que indican que la maduración folicular está comprometida cuando el balance energético de las vacas es negativo y las concentraciones de IGF1 y/o insulina están reducidas, como ocurre en el posparto temprano (Wathes et al., 2003; Webb et al., 2004).

Otros integrantes importantes de este sistema son los receptores que se activan mediante la unión al ligando. El receptor tipo 1 (IGFR1) interviene en la mayoría de las acciones de ambos ligandos. Se une con alta afinidad a IGF1, en menor grado a IGF2 y con muy baja afinidad a la insulina (Giudice, 1992; Jones y Clemmons, 1995; Monget et al., 2002). Cuando el IGF1 se une a su receptor específico, IGFR1, se produce un cambio conformacional activándolo y provocando una cascada de fosforilación intracelular (Kavran et al., 2014). Si bien la insulina y el IGF1 poseen receptores diferentes, altas concentraciones de insulina pueden reconocer al IGFR1, y cuando ambos receptores están presentes en la misma célula son capaces de formar híbridos IGFR-IR (Figura 1), los cuales unen tanto IGF1 como insulina (Webb et al., 2004). El receptor tipo 2 (IGFR2), liga con alta afinidad a IGF2 y moléculas con residuos de manosa 6-fosfato, y con baja afinidad a IGF1 (Giudice, 1992; Jones y Clemmons, 1995; Monget et al., 2002). La función principal de IGFR2 sería mediar el recambio de enzimas lisosomales y participar en la degradación de IGF2 luego de su internalización (Giu-dice, 1992; Monget et al., 2002).

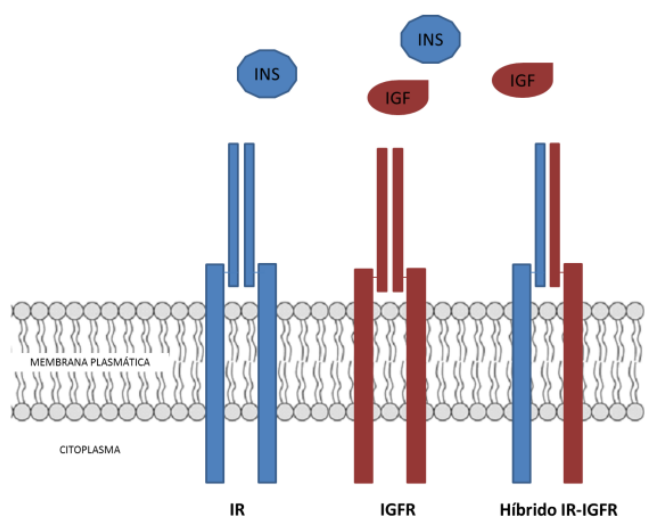

Figura 1. Estructura de los receptores de insulina (IR) y de IGF (IGFR). Se observa la formación de híbridos entre receptores de insulina y de IGF cuando ambos receptores están presentes en la misma célula (Adaptado de Jones y Clemmons, 1995).

Se conocen en el bovino seis proteínas de unión estructuralmente relacionadas (IGFBP1 a 6), con elevadas y diferentes afinidades por los dos ligandos (Jones y Clemmons, 1995; Monget et al., 1996, Hwa et al., 1999) que participan en el transporte de los IGFs en la circulación, regulando la biodisponibilidad a sus receptores y modulando el crecimiento celular (Cantero et al., 2007). Además prolongan la vida media de los ligandos, regulan los efectos endocrinos de los factores de crecimiento y pueden inhibir la acción de los IGFs en las células blanco cuando se encuentran unidas al ligando o favorecer su acción cuando son escindidas y liberan al mismo (Giudice, 1992; Rajaram et al., 1997; Monget et al., 2002). 
Otros componentes del sistema IGF son las IGFBPs proteasas que degradan a las IGFBPs y disminuyen la afinidad de unión por los ligandos. Además de ser sintetizada por la placenta, el ARNm para esta proteína ha sido detectado en células de la granulosa de folículos ováricos humanos (Conover et al., 2001) y de animales domésticos (Mazerbourg et al., 2001; Monget et al., 2003). Esta metaloproteasa escinde especialmente a IGFBP4 y se discute su actividad sobre IGFBP2 y 5 (Spicer, 2004). Además, se conocen otras metaloproteasas, las calicreínas, que están presentes en el LF y pueden degradar otras IGFBPs, incluyendo a IGFBP2, 3 y 5 (Mazerbourg et al., 2001; Conover, 2012).

\section{Control de la biodisponibilidad de IGFs en el ovario}

La biodisponibilidad de los IGFs está regulada por las IGFBPs que se unen a los ligandos con un grado de afinidad del mismo orden de magnitud que a sus receptores (Monget et al., 2002). En consecuencia se produce un secuestro de los IGFs por parte de las proteínas ligadoras generando un impedimento estérico que disminuye así la posibilidad de unirse al receptor y ejercer su acción (Forbes et al., 2012). Los cambios en las concentraciones de las IGFBPs dependen de cambios en la síntesis local, regulación hormonal o modificaciones postraduccionales debidas a degradación proteolítica que disminuyen la afinidad por los ligandos (Spicer et al., 2004). Esta última modificación se da por proteasas específicas que escinden a las IGFBPs generando fragmentos $\mathrm{N}$ - y C-terminales con menor grado de afinidad por los ligandos $y$, en consecuencia, se incrementa la biodisponibilidad del IGF libre para unirse al receptor específico (Brogan et al., 2010; Forbes et al., 2012). La principal proteasa en bovinos es la PAPP-A, una metaloproteasa altamente específica de unión a los glicosaminoglicanos presentes en la superficie de las células (Conover et al., 2001).

Se ha demostrado que la PAPP-A es responsable del clivaje de la IGFBP4 en el líquido folicular ovárico (Conover et al., 1999) y es secretada por las células de la granulosa (Conover et al., 2001; Rodríguez et al., 2015), células vasculares del músculo liso (Bayes-Genis et $a l .2001 \mathrm{~b})$ y células estromales del endometrio (Giudice et al.2002). La PAPP-A, cliva a la IGFBP4 produciendo fragmentos proteolíticos con menor capacidad de unión al ligando, por lo que se incrementa el IGF disponible para unirse al IGFR1 y activar una serie de reacciones de fosforilaciones intracelulares (Spicer, 2004; Aad et al., 2006). Esta actividad proteolítica de PAPP-A depende de la presencia de IGF y es una característica de los folículos dominantes. La disminución de IGFBP4 y 5 se debe a la degradación por parte de dichas proteasas, lo que permite que se incrementen los niveles de IGFs libres disponibles para cumplir acciones a nivel de la foliculogénesis, preparando al folí- culo y el ovocito para una ovulación y fertilización satisfactoria (Spicer, 2004).

Los mecanismos por los cuales la PAPP-A escinde a IGFBP4 y 5 difieren. Por un lado, para el clivaje de la IGFBP4 es necesaria la presencia de IGF1 o 2 , de esta manera, la IGFBP4 se une a IGF con alta afinidad y previene su interacción con los receptores de la superficie de la célula blanco (Qin et al. 2000; Laursen et al. 2001). Sólo cuando la IGFBP4 está unida al IGF, se convierte en sustrato para PAPP-A (Conover, 2012). En contraste, para que la PAPP-A clive a la IGFBP5 no se requiere la presencia de IGF, aunque la acción mejora ligeramente en presencia del ligando (Aad et al., 2006; Gaidamauskas et al., 2013). La superficie celular unida a PAPP-A es proteolíticamente activa (Laursen et al.2002a). Por lo tanto, la degradación de IGFBP-4 se produce en las proximidades del IGF1R, aumentando la posibilidad de que al liberar el IGF se estimule el receptor (Oxvig, 2015; Figura 2). Además, es posible que los fragmentos proteolíticos de IGFBP4 tengan un efecto independiente de la presencia de IGF en las células foliculares (Forbes et al., 2012). Finalmente, el incremento de la expresión de PAPP-A coincide con eventos proteolíticos asociados con la ovulación, por lo que participaría escindiendo sustratos críticos de dicho proceso (Mazerbourg et al., 2001).

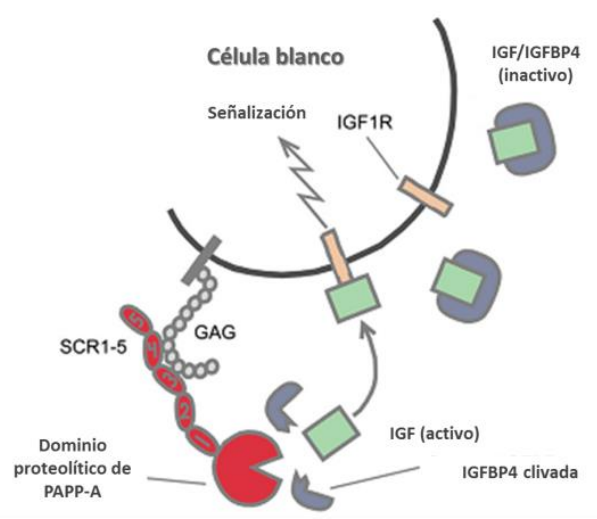

Figura 2. El rol de la PAPP-A y la IGFBP4 en el sistema IGF. La PAPP-A unida a los proteoglicanos de la superficie celular causa el clivaje proteolítico de la IGFBP4. Esto ocurre en las proximidades del IGFR1, incrementando la posibilidad que el IGF liberado se una al receptor (Laursen et al.2007). La unión a la superficie está mediada por moduladores de la PAPP-A como SCR3 y SCR4 (Adaptada de Oxvig, 2015).

\section{Activación y señalización del sistema IGF}

La activación del receptor se inicia mediante la unión del ligando. El ligando se une a su receptor específico, se produce un cambio conformacional y de esta manera se activa (Kavran et al., 2014). Una vez activado comienza una cascada de señalización que media el cre- 
cimiento folicular y la inhibición de la apoptosis (Kwiontkiewicz y Giudice, 2009; Sánchez et al., 2014), entre otras acciones. Dependiendo del tipo de célula, el IGF1 activa la vía de la fosfatidilinositol3-quinasa (PI3K) y/o a la cascada de las proteínas quinasas activadas por mitógenos (MAPK; Figura 3; LeRoith et al., 1995; Poretsky et al., 1999).

EI IGF1 se une a la subunidad extracelular de su receptor específico e induce un cambio conformacional y la autofosforilación del residuo tirosina de la subunidad $\beta$ que provoca la activación del receptor. La fosforilación de la tirosina causa el reclutamiento de sustratos intracelulares (IRS-1, IRS-2, SHC, Grb2). A su vez, dichos sustratos unen e incorporan otras proteínas intracelulares como la PI3K y las proteínas activadoras de GTPasas (GAP) de Ras que originan las dos vías de señalización más frecuentes (Belfiore et al., 2009).

La señalización por la vía de PI3K activa a una proteína quinasa $B$ (PKB o AKT), un mediador de la proliferación y supervivencia celular (Kwintkiewicz y Giudice, 2009). La PI3K se asocia a IRS a través de la subunidad regulatoria (p85), que recluta a la subunidad catalítica de PI3K ( 1110 ) en la membrana plasmática, en donde fosforila la fosfatidilinositol 4,5-bifosfato (PIP2) a fosfatidilinositol 3,4,5-trifosfato (PIP3). La PIP3 a su vez, recluta la proteína quinasa AKT y sigue la activación por la quinasa 1 dependiente del fosfoinositol (PDK). La AKT regula la traducción de ARNm responsables del crecimiento y metabolismo celular (Belfiore et al., 2009).

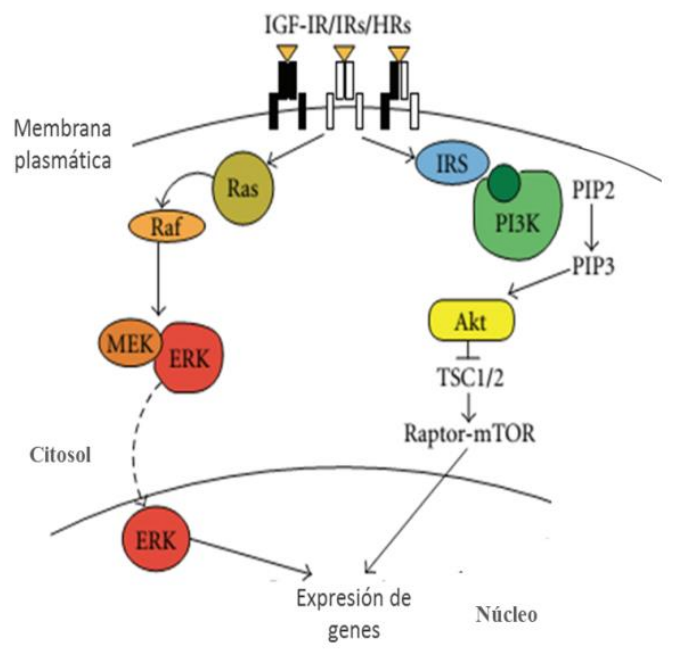

Figura 3. Representación gráfica de las vías de transducción de señales reguladas por las gonadotropinas (HRs) y los IGFs (IGFR-I). Se estimulan receptores nucleares involucrados en el desarrollo, función e integridad del folículo (adaptación de Belfiore y col., 2009 y Kwintkiewicz y Giudice, 2009).
En la vía de señalización de las MAPK se encuentra involucrada una familia de quinasas reguladas por señales extracelulares (ERK) capaz de regular la proliferación, diferenciación y la supervivencia celular. Esta segunda vía de señalización involucra a Ras, una proteína de unión a GTP que es activa cuando está unida a GTP y es inactivada por GDP. Ras es activada mediante mSOS que se une a un adaptador, Grb2, capaz de acoplar el complejo Ras/mSOS al receptor mediante la unión de las proteínas Shc y el IRS. Luego de la activación, Ras se recluta a la membrana y activa la quinasa serina/ treonina Raf, que fosforila la quinasa MEK con especificidad dual que a su vez fosforila y activa ERK1/2. Las ERK1/2 inactivas están localizadas principalmente en el citoplasma donde forman un heterodímero MEK/ERK. Luego de la activación, ERK1/2 se traslocan al núcleo donde fosforilan sus-tratos involucrados en la activación de la transcripción de importantes genes, o bien fosforilan numerosos sustratos en el citoplasma implicados en el crecimiento celular y supervivencia (Belfiore et al., 2009).

\section{Participación del sistema IGF en el ovario y su relación con el ambiente hormonal}

Si bien, como se detalló previamente, el hígado es la principal fuente de IGF (Lucy, 2000; Velazquez et al., 2008), los niveles de IGF1 y 2 pueden ser regulados localmente en diferentes tejidos, entre ellos, el ovario. La expresión de IGFs en las células de la granulosa estaría regulada durante la selección del folículo dominante (Fortune et al., 2004). Si bien se han demostrado los efectos de ambos ligandos sobre la proliferación y diferenciación de células de la granulosa, el IGF1 ejercería las principales funciones (Hastie y Haresing, 2006a) proponiéndolo como el factor más relevante en la regulación de la foliculogénesis en bovinos (Armstrong et al., 2000).

El desarrollo folicular está regulado principalmente por la FSH y la LH, y el sistema IGF actúa en sinergia con dichas hormonas, estimulando la diferenciación celular (Spicer et al., 2000; Davidson et al., 2002). La regulación de la foliculogénesis es un proceso complejo en el cual los IGFs son relevantes por la interrelación con la FSH, hormonas esteroides, otros factores de crecimiento y hormonas que controlan el desarrollo folicular (Souza et al., 2007). Los IGFs actúan en el ovario como un mecanismo de amplificación local para la acción de las gonadotropinas, lo que facilita el desarrollo folicular, mientas que las IGFBPs parecen inhibir este proceso y llevar a la atresia (Souza et al., 2007). El crecimiento folicular y la dominancia están controlados por una serie de eventos hormonales que llevan a cambios en la expresión de varias proteínas reguladoras en las células de la teca y de la granulosa incluyendo a las IGFBPs (Ginther et al., 2002, Monget et al., 
2002). Debido a que existe una estrecha relación entre las concentraciones de IGFBPs y la fertilidad (Grimard et al., 2013), diferentes autores postularon que IGFBP2, 3, 4 y 5 son las principales IGFBPs reguladas durante el crecimiento folicular, presentando sus menores concentraciones durante la dominancia (Stewart et al., 1996; Armstrong y col., 1998; Hastie y Haresign, 2006a). En LF de ovarios bovinos se han detectado las IGFBP 2 a 5 (Spicer y Echternkamp, 1995; Funston et al., 1996) y bajas cantidades de IGFBP1 y 6 (Nicholas et al., 2002).

En bovinos, el IGF1 aumenta la liberación de la LH estimulada por la $\mathrm{GnRH}$, sin modificar el número de receptores para dicha hormona e interactúa con el 17 $\beta$-estradiol para incrementar la respuesta a este factor liberador hipotalámico (Souza et al., 2007). Por otro lado, se ha demostrado que la expresión de IGF1 (Hsu y Hammond, 1987; Samaras et al., 1996) y su ARNm está modulada por la FSH (Hastie y Haresing, 2006a). Algunos autores demostraron que IGF1 actúa sinérgicamente con FSH para estimular la proliferación y la esteroidogénesis de las células de la granulosa in vitro (Hammond et al., 1991; Spicer y Chamberlain, 2000). El incremento de la respuesta a la FSH culmina, mediante los factores de regulación autocrina (IGF1 entre otros) al final de la selección folicular, con la expresión y síntesis de receptores de $\mathrm{LH}$ en las células de la granulosa. Además, la LH estimula la actividad de la aromatasa, y mantiene la dominancia hasta el momento de la ovulación (Souza et al., 2007). Los niveles de IGFs no varían durante el desarrollo folicular y atresia a diferencia de los niveles de IGFBP2, 4 y 5 que disminuyen drásticamente durante el crecimiento folicular hasta desarrollarse el folículo dominante y aumentan en la atresia de bovinos, cerdos, ovinos, humanos y caballos (Austin et al., 2001; Ginther et al., 2002; Monget et al., 2002; Spicer, 2004). Las IGFBP2 y 4 disminuyen a medida que los folículos llegan a ser preovulatorios (Spicer, 2004). La disminución en la producción de IGFBPs podría deberse además, a una alta actividad biológica de IGF producida localmente o a un aumento de la respuesta a las gonadotropinas del folículo (Armstrong y Webb, 1997). La regulación hormonal en la síntesis de las IGFBPs es específica según la especie y el tipo de célula. En este sentido, la FSH regula la producción de IGFBP4 y 5 en células de la granulosa de ratones y cerdos pero no en bovinos. Por otro lado, la LH y el estradiol disminuyen la producción de IGFBP4 en células de la granulosa bovina mientras que no tienen efecto en células de la teca (Spicer et al., 2004). En folículos atrésicos se encuentran altos niveles de IGFBPs con bajos niveles de IGFs y baja actividad proteasa (Monget et al., 1993). Por el contrario, en los folículos dominantes, los IGFs se presentan en altos niveles al igual que los niveles de proteasas. Las concentraciones de IGFBP3 se mantienen intactas, mientras que las concentraciones de las IGFBP2, 4 y 5 son significativamente menores en folículos dominantes que en subordinados (Nicholas et al., 2002).
La actividad de la PAPP-A en LF bovino es inducida por la FSH y, durante la selección folicular, la actividad proteolítica aumenta con el incremento de $17 \beta$-estradiol y el IGF1 libre en el mismo (Aad et al., 2006). A los dos días de la primera onda folicular, la actividad proteolítica es más alta en folículos dominantes en comparación con los subordinados de mayor tamaño, sugiriendo un rol de la proteasa específica de IGFBP4 en el establecimiento de la dominancia folicular (Spicer et al., 2004). En folículos terciarios bovinos existe una alta actividad proteasa en IGFBP4 y 5 con reducida actividad de unión de la IGFBP4 y un aumento de IGF libres (Spicer, 2004; Aad et al., 2006). En este sentido, la expresión de la PAPP-A, como componente principal de la degradación de IGFBP4 en el LF (Besnard et al., 1996b; Monget et al., 2003) tiene tendencia a aumentar con el desarrollo del folículo (Santiago et al., 2005). Estos altos niveles de PAPP-A mantendría las menores concentraciones de IGFBP4 (Mazerbourg et al., 2001; Rivera y Fortune, 2001; Fortune et al., 2004). Consecuentemente, se favorecería la mayor disponibilidad de IGF1 durante el crecimiento folicular (Spicer et al., 1993; 1996; Fortune et al., 2004).

\section{Expresión de los diferentes componen- tes del sistema IGF en la COD}

La expresión y mecanismos de acción de algunos factores intraováricos como el sistema IGF han sido ampliamente estudiados en diferentes especies en condiciones fisiológicas. Sin embargo, en situaciones patológicas como lo es la COD, lo reportado es escaso. La comprensión de estos mecanismos regulatorios contribuirá a esclarecer procesos que ocurren durante situaciones patológicas que afectan la ciclicidad ovárica normal del ganado.

Si bien ha sido claramente establecido que el IGF1 se expresa en las células de la granulosa de roedores y cerdos, la expresión génica del IGF1 en rumiantes es controversial. En animales con COD se demostró expresión génica de IGF1 en células de la granulosa bovina, con niveles no detectables en células de la teca (Spicer y Echternkamp 1995; Armstrong et al., 2000, Hastie y Haresing, 2006a, Rodríguez et al., 2013). Se ha sugerido que además de estar involucrado en la patogénesis, el IGF1 está involucrado en el mantenimiento de la COD en bovinos (Zulu et al., 2002; Probo et al., 2011). En estudios previos, se evidenció una menor expresión proteica de este ligando en la pared de folículos quísticos respecto a folículos de animales controles (Ortega et al., 2008). Por otro lado, se detectaron niveles séricos de IGF1 similares en animales controles y con COD, con una disminución en el LF de animales con COD respecto a los controles (Beam y Butler, 1997, 1998; Zulu et al., 2002; Ortega et al., 2008). Estas diferencias podrían deberse a una menor internalización del IGF1 sistémico, a una alteración 
en la regulación de la síntesis de IGF1 en el ovario de animales con COD, sin descartar la regulación por parte de las IGFBPs con acción local en el ovario (Sánchez et al., 2014; Rodríguez et al., 2015). Las IGFBPs poseen un efecto inhibitorio bloqueando la unión de los ligandos a sus receptores, o un efecto estimulador protegiendo la degradación de los IGFs (Grimard et al., 2013). Dichos efectos dependen de cambios postraduccionales como fosforilaciones, degradación proteolítica o unión a la matriz extracelular (Monget y Bondy, 2000). Se han documentado variaciones en las concentraciones de las IGFBPs en LF durante el crecimiento y desarrollo folicular en bovinos (de la Sota et al., 1996; Stewart et al., 1996), ovinos (Perks y Wathes, 1996), y cerdos (Yuan et al., 1996). Rodríguez et al (2011; 2013) encontraron expresión de IGFBP2, 3, 4 y 5 en células de la granulosa de folículos en desarrollo y en quistes. En folículos quísticos se encontraron los menores niveles de expresión génica y proteica para IGFBP3. Sin embargo, es la proteína con más actividad detectada en LF lo que estaría indicando que la acción local de IGBP3 no es producto de la síntesis in situ sino que podría haber una contribución sistémica (Wathes et al., 2003; Santiago et al., 2005; Rodríguez et al., 2013). Los niveles de expresión de IGFBP2, 4 y 5 detectados en quistes son similares a los observados en folículos controles (Rodríguez et al., 2011; 2013). Por otro lado, existe una disminución en la actividad de IGFBP4 y 5 en la medida que ocurre el crecimiento del folículo, determinando la menor actividad en los quistes (Monget et al., 1993, Spicer, 2004, Aad et al., 2006; Rodríguez et al., 2013). Esto indicaría un control hormonal en la síntesis de algunas IGFBPs y proteínas asociadas como las proteasas, evidenciando que IGFBP4 y 5 serían más sensibles a la degradación proteolítica que las demás IGFBPs (Spicer, 2004; Aad et al., 2006; Sudo et al., 2007; Rodríguez et al., 2015).

En cuanto a la información sobre la expresión y regulación del ARNm y proteínas IGFBP1 y 6 es muy limitada en ovarios de rumiantes tanto en condiciones fisiológicas como patológicas (Nicholas et al., 2002; Rodríguez et al., 2013) lo que sugiere que estas IGFBPs no serían relevantes en la fisiología del ovario en rumiantes (Kamangar et al., 2006).

El IGFR1 media las acciones biológicas de IGF1 y 2, teniendo un rol importante en el desarrollo folicular (Echternkamp et al., 2004; Yang et al., 2013). En folículos quísticos bovinos existe una mayor expresión de IGFR1 en células de la granulosa y niveles crecientes del mismo a medida que aumenta el tamaño del folículo (Lucy, 2008; Silva et al., 2009; Rodríguez et al., 2015). Por otro lado, hay variaciones en ciertos moduladores de la cascada de señalización PI3K (Hein et al., 2015). Esta modulación diferencial de los componentes de esta vía de señalización o la posibilidad de que PI3K sea reclutada y activada por hormonas o factores de crecimiento como el sistema IGF, podrían estar implicados en las variaciones de los niveles de IGFR1 detectados. Diversos estudios sugie- ren una regulación de diferentes componentes del sistema IGF por las gonadotropinas (Spicer et al., 1994; Hastie y Haresing, 2006a; 2006b; 2008; Kwintkiewicz y Giudice, 2009). En animales con quistes, se produce una alteración hormonal que incluye una inadecuada producción de FSH, frecuencias de los pulsos de LH alteradas, inhibición del pico preovulatorio de esta gonadotropina que impiden un funcionamiento ovárico normal (Battaglia et al., 2000; Williams et al., 2001; Peter, 2004), por lo que la expresión del receptor podría verse modificada por el ambiente hormonal alterado en animales con COD. Algunos estudios sugieren que el $17 \beta$-estradiol estimularía la proliferación celular mediante la activación del IGFR1 independiente de los ligandos (Song et al., 2004, KamangaSollo et al., 2013). Sin embargo, otros autores postulan que la actividad de este receptor es dependiente del ligando, el IGF se une, produce un cambio conformacional provocando su activación (Kavran et al., 2014). Así, los altos niveles de IGFR1 en quistes podrían estar estimulados por los niveles de $17 \beta$-estradiol tendientes a aumentar en estas estructuras (Amweg et al., 2013), cuando las concentraciones de IGF1 son bajas como ha sido demostrado previamente en quistes (Ortega et al., 2008). De esta manera, el aumento de la expresión del receptor se debería a la necesidad de incrementar la posibilidad de respuesta frente a los bajos niveles de IGF1 detectados en quistes (Ortega et al., 2008; Rodríguez et al., 2015). Así, los quistes serían capaces de mantener las respuestas a IGF1, tales como la proliferación (Salvetti et al., 2010) y la esteroidogénesis activas (Ortega et al., 2008; Amweg et al., 2013).

La biodisponibilidad de los IGFs es el resultado de una relación entre las IGFBPs y sus proteasas (Mazerbourg et al., 2001; Boldt y Conover., 2007; Ning et al., 2008). La PAPP-A es la principal proteasa reguladora de los niveles de IGF1 libre en el folículo dominante bovino (Mazerbourg et al., 2001; Spicer et al., 2004; Sánchez et al., 2014). En células de la granulosa de quistes, se observó la menor expresión génica de esta proteasa en relación a folículos controles (Mazerbourg et al., 2001; Santiago et al., 2005; Sánchez et al., 2014; Rodríguez et al., 2015). Por otra parte, la proteasa secretada es mayor en el LF de quistes respecto a los folículos terciarios de menor tamaño (Mazerbourg et al., 2001; Monget et al., 2003; Rivera y Fortune, 2003b; Rodríguez et al., 2015). Este aumento de la PAP-A en quistes, junto a la disminución de IGFBP4 en el LF de los quistes, evidencian una mayor actividad proteolítica de esta enzima, que mantiene la disponibilidad de los bajos niveles de IGF1 en quistes (Ortega et al., 2008) para la esteroidogénesis, la diferenciación y persistencia folicular.

\section{Conclusiones}

Considerando a los componentes del sistema IGF como reguladores importantes del desarrollo folicular, 
esteroidogénesis y diferenciación celular entre otros procesos intraováricos, una falla en los mecanismos de transcripción y regulación de dicho sistema puede ocasionar alteraciones en el ciclo estral normal y conducir a importantes problemas reproductivos como lo es la COD.

Como se ha mencionado anteriormente, existen diferentes cambios a nivel celular y molecular del sistema IGF que podrían conducir al desarrollo del quiste. Si bien existe información que ha permitido dilucidar cambios en dicho sistema que podrían asociarse a la etiopatogenia de esta enfermedad, aún son necesarios estudios en niveles iniciales, previos a la instauración de la enfermedad, para poder comprender las causas de la misma.

\section{Bibliografía}

Aad PY, Voge JL, Santiago CA, Malayer JR, Spicer LJ. 2006. Real time RT-PCR quantification of pregnancyassociated plasma proteinA mRNA abundance in bovine granulosa and theca cells: effects ofhormones in vitro. Domest. Anim. Endocrinol. 31: 357-372.

Adashi EY. 1998. The IGF family and folliculogenesis. J. Reprod. Immunol. 39: 13-19.

Amweg AN, Salvetti NR, Stangaferro ML, Paredes A, Lara HH, Rodríguez FM, Ortega HH. 2013. Ovarian localization of 11b-hydroxysteroid dehydrogenase (11bHSD): effects of ACTH stimulation and its relationship with bovine cystic ovarian disease. Domest. Anim. Endocrinol. 45:126-140.

Armstrong DG, Gutierrez CG, Baxter G, Glazyrin AL, Mann GE, Woad KJ, Hogg CO, Webb R. 2000. Expression of mRNA encoding IGF-I, IGF-II and type 1 IGF receptor in bovine ovarian follicles. J Endocrinol. 165: 101-113.

Armstrong DG, Webb R. 1997. Ovarian follicular dominance: the role of intraovarian growth factors and novel proteins. Reproduction 2:139-146.

Austin EJ, Mihm M, Evans ACO, Knight PG, Ireland JLH, Ireland JJ, Roche JF. 2001. Alterations in intrafollicular regulatory factors and apoptosis during selection of follicles in the first follicular wave of the bovine estrous cycle. Biol. Reprod. 64: 839-848

Battaglia DF, Krasa HB, Padmanaban V, Viguie C, Karsch FJ. 2000. Endocrine alterations that underlie endotoxinmediated disruption of the follicular phase in ewes. Biol. Reprod. 62: 45-53.

Bayes-Genis A, Conover CA, Overgaard MT, Bailey KR, Christiansen $M$, Holmes DR Jr, Virmani R, Oxvig C, Schwartz RS. 2001. Pregnancy-associated plasma protein $\mathrm{A}$ as a marker of acute coronary syndromes. $\mathrm{N}$. Engl. J. Med. 345: 1022-1029.

Beam SW, Butler WR. 1997. Energy balance and ovarian follicle development prior to the first ovulation postpartum in dairy cows receiving three levels of dietary fat. Biol. Reprod. 56: 133-142.
Beam SW, Butler WR. 1998. Energy balance, metabolic hormones, and early postpartum follicular development in dairy cows fed prilled lipid. J. Dairy. Sci. 81: 121-131.

Belfiore A, Frasca F, Pandini G, Sciacca L, Vigneri R. 2009. Insulin receptor isoforms and insulin receptor/insulinlike growth factor receptor hybrids in physiology an d disease. Endocr. Rev. 30:586-623.

Besnard N, Pisselet C, Monniaux D, Locatelli A, Benne F, Gasser F, Hatey F, Monget P. 1996b. Expression of messenger ribonucleic acids of insulin-like growth factor binding protein-2, -4 , and -5 in the ovine ovary: localization and changes during growth and atresia of antral follicles. Biol. Reprod. 55:1356-1367.

Boldt HB, Conover CA. 2007. Pregnancy-associated plasma protein-A (PAPP-A): a local regulator of IGF bioavailability through cleavage of IGFBPs. Growth. Horm. IGF Res. 17:10-18.

Brogan RS, Mix S, Puttabyatappa M, VandeVoort CA, Chaffin CL. 2010. Expression of the insulin-like growth factor and insulin systems in the luteinizing macaq ue ovarian follicle. Fertil. Steril. 93: 1421-1429

Cantero M, Cortés C, Bernal Y, Ansola C, Sanchez- Gómez M, Bermúdez A, Marín M. 2007. Insulin-like growth factors (IGF1 y 2) in serum of patients with mole hyditiform. Revista Electrónica Hominis. 1:7

Cattaneo L, Barberis FC, Stangaferro ML, Signorini ML, Ruiz MF, Zimmermann R, Bo GA, Hein GJ. Ortega HH. 2014. Evaluación de indicadores metabólicos y bioquímicos sanguíneos en vacas en lactancia con Enfermedad Quística Ovárica. InVet. 15: 7-15

Conover CA, Oxvig C, Overgaard MT, Christiansen M, Giudice LC. 1999. Evidence that the insulin-like growth factor binding protein-4 protease in human ovarian follicular fluid is pregnancy associated plasma protein-A. J Clin. Endocrinol. Metab. 84:4742-4745

Conover CA, Faessen GF, Ilg KE, Chandrasekher YA, Christiansen M, Overgaard MT, Oxvig C, Giudice LC. 2001. Pregnancy-associated plasma protein-a is the insulinlike growth factor binding protein-4 protease secreted by human ovarian granulosa cells and is a marker of dominant follicle selection and the corpus luteum. Endocrinology 142:2155

Conover CA. 2012. Key questions and answers about pregnancy-associated plasma protein-A. Trends Endocrinol. Metab. 23:5

Davidson TR, Chamberlain CS, Bridges TS, Spicer LJ. 2002. Effect of Follicle Size on In Vitro Production of Steroids and Insulin-Like Growth Factor (IGF)-I, IGF-II, and the IGF-Binding Proteins by Equine Ovarian Granulosa Cells. Biol. Reprod. 66:1640-1648.

de la Sota RL, Simmen FA, Diaz T, Thatcher WW. 1996. Insulin-Like Growth Factor System in Bovine First-Wave Dominant and Subordinate Follicles. Biol. Reprod. 55: 803-812.

Echternkamp SE, Roberts AJ, Lunstra DD, Wise T, Spicer LJ. 2004. Ovarian follicular development in cattle selected for twin ovulations and births. J Anim. Sci. 82:4 59-71

Etherton TD, Bauman DE. 1998. Biology of somatotropin in growth and lactation of domestic animals. Physiol. Rev. 78: 745-761. 
Forbes BE, McCarthy P, Norton RS. 2012. Insulin-like growth factor binding proteins: a structural perspective. Front. Endocrinol. (Lausanne). 3: 38.

Fortune JE, Rivera GM, Yang MY. 2004. Follicular development: the role of the follicular microenvironment in selection of the dominant follicle. Anim. Reprod. Sci. 82-83: 109-126

Funston RN, Seidel GE, Klindt J, Roberts AJ. 1996. Insulin-Like Growth Factor I and Insulin-Like Growth Factor-Binding Proteins in Bovine Serum and Follicular Fluid before and after the Preovulatory Surge of Luteinizing Hormone. Biol. Reprod. 55: 1390-1396

Gaidamauskas E, Gyrup C, Boldt HB, Schack VR, Overgaard MT, Laursen LS, Oxvig C. 2013. IGF dependent modulation of IGF binding protein (IGFBP) proteolysis by pregnancy-associated plasma protein-A (PAPP-A): Multiple PAPP-A-IGFBP interaction sites. Biochim. Biophys. 1830: 2701-2709.

Ginther OJ, Beg MA, Bergfelt DR, Kot K. 2002. Activin A, $17 \beta$ estradiol, and Free Insulin-Like Growth Factor I in Follicular Fluid Preceding the Experimental Assumption of Follicle Dominance in Cattle. Biol. Reprod. 67: 1419.

Giudice L. 1992. Insulin-like growth factors and ovarian follicular development. Endocrinology 13 :641-669.

Giudice LC, Conover CA, Bale L, Faessen GH, Ilg K, Sun I, Imani B, Suen LF, Irwin JC, Christiansen M, Overgaard MT, Oxvig C. 2002. Identification and regulation of the IGFBP-4 protease and its physiological inhibitor in human trophoblasts and endometrial stroma: evidence for paracrine regulation of IGF-II bioavailability in the placental bed during human implantation. J. Clin. Endocrinol. Metab. 87: 2359-2366.

Grimard B, Marquant-Leguienne B, Remy D, Richard C, Nuttinck F, Humblot $P$, Ponter AA. 2013. Postpartum variations of plasma IGF and IGFBPs, oocyte production and quality in dairy cows: relationships with parity and subsequent fertility.Reprod Domest Anim. 48:183-94

Hammond JM, Mondschein JS, Samaras SE, Canning SF. 1991. The ovarian insulin-like growth factors, a local amplification mechanism for steroidogenesis and hormone action. J. Steroid. Biochem. Mol. Biol. 40: 411-416.

Hastie PM, Haresign W. 2006a. Expression of mRNAs encoding insulin-like growth factor (IGF) ligands, IGF receptors and IGF binding proteins during follicu lar growth and atresia in the ovine ovary throughout the oestrous cycle. Anim. Reprod. Sci. 92: 284-299.

Hastie PM, Haresign W. 2006b. A role for LH in the regulation of expression of mRNAs encoding components of the insulin-like growth factor (IGF) system in the ovine corpus luteum. Anim. Reprod. Sci. 96: 196-209

Hastie PM, Haresign W. 2008. Modulating peripheral gonadotrophin levels affects follicular expression of mRNAs encoding insulin-like growth factors and receptors in sheep. Anim. Reprod. Sci. 109: 110-123.

Hein GJ, Panzani CG, Rodríguez FM, Salvetti NR, Díaz PU, Gareis NC, Benítez GA, Ortega HH, Rey F. 2015. Impaired insulin signaling pathway in ovarian follicles of cows with cystic ovarian disease. Anim. Reprod. Sci. 9. pii: S0378-4320(15)00057-3.
Hsu CJ, Hammond JM. 1987. Gonadotropins and estradiol stimulate immunoreactive insulin-like growth factor-I production by porcine granulosa cells in vitro. Endocrinology 120: 198-207.

Hwa V, Oh Y, Rosenfeld RG. 1999. The insulin-like growth factor-binding protein (IGFBP) superfamily. Endocr. Rev. 20:761-287.

Jones JI, Clemmons DR. 1995. Insulin-like growth factors and their binding proteins: biological actions. Endocrinology 16: 3-34.

Kamangar BB, Gabillard JC, Bobe J.2006. Insulin-like growth factor-binding protein (IGFBP)-1, $-2,-3,-4,-5$, and -6 and IGFBP-related protein 1 during rainbow trout postvitellogenesis and oocyte maturation: molecular characterization, expression profiles, and hormonal regulation. Endocrinology 147:2399-2410.

Kamanga-Sollo E, White ME, Weber WJ, Dayton WR. 2013. Role of estrogen receptor- $\alpha$ (ESR1) and the type 1 insulin-like growth factor receptor (IGFR1) in estradiolstimulated proliferation of cultured bovine satellite cells. Domest. Anim. Endocrinol. 44:36-45

Kavran JM, McCabe JM, Byrne PO, Connacher MK, Wang Z, Ramek A, Sarabipour S, Shan Y, Shaw DE, Hristova K, Cole PA, Leahy DJ. 2014. How IGF-1 activates its receptor. Elife. 25: 3 .

Kwiontkiewicz J, Giudice LC. 2009. The Interplay of InsulinLike Growth Factors, Gonadotropins, and Endocrine Disruptors in Ovarian Follicular Development and Function. Semin. Reprod. Med. 27: 43-51

Laursen LS, Overgaard MT, Soe R, Boldt HB, Sottrup-Jensen L, Giudice LC, Conover CA, Oxvig C. 2000. Pregnancyassociated plasma protein-A (PAPP-A) cleaves insulinlike growth factor binding protein (IGFBP)-5 independent of IGF: implications for the mechanism of IGFBP-4 proteolysis by PAPP-A. FEBS Lett 504: 36-40.

Laursen LS, Overgaard MT, Nielsen CG, Boldt HB, Hopmann $\mathrm{KH}$, Conover CA, Sottrup-Jensen L, Giudice LC, Oxvig C. 2002a. Substrate specificity of the metalloproteinase pregnancy-associated plasma protein-A (PAPP-A) assessed by mutagenesis and analysis of synthetic peptides: substrate residues distant from the scissile bond are critical for proteolysis. Biochem. J. 367: 31-40

Laursen LS, Kjaer-SorensenK, Andersen MH, Oxvig C. 2007. Regulation of insulin-like growth factor (IGF) bioactivity by sequential proteolytic cleavage of IGF binding protein-4and-5. Mol. Endocrinol. 21: 1246-1257

LeRoith D, Werner H, Beitner-Johnson D, Roberts CT Jr. 1995. Molecular and cellular aspects of the insulin-like growth factor I receptor. Endocr. Rev.16: 143-163.

Lucy M. 2000. Regulation of ovarian follicular growth by somatotropin and insulin-like growth factors in cattle. J. Dairy. Sci. 83: 1635-1647.

Lucy M. 2008. Functional differences in the growth hormone and insulin-like growth factor axis in cattle and pigs: implications for post-partum nutrition and reproduction. Reprod. Domest. Anim. 43:31-39.

Mazerbourg S, Overgaard MT, Oxvig C, Christiansen M, Conover C, Laurendeau I, Vidaud M, Tosser-klopp G, Zapf J, Monget P. 2001. Pregnancy-Associated Plasma Protein-A (PAPP-A) in Ovine, Bovine, Porcine, and Equine Ovarian Follicles: Involvement in IGF Binding 
Protein-4 Proteolytic Degradation and mRNA Expression During Follicular Development. Endocrinology 142: $5243-5253$

Monget P, Monniaux D, Pisselet C, Durand P. 1993. Changes in insulin-like growth factor-I (IGF-I), IGF-II, and their binding proteins during growth and atresia of ovine ovarian follicles. Endocrinology 132: 1438-1446.

Monget P, Besnard N, Huet C, Pisselet C, Monniaux D. 1996. Insulin-like growth factorbinding proteins and ovarian folliculogenesis. Horm. Res. 45:211-217.

Monget P, Bondy C. 2000. Importance of the IGF system in early folliculogenesis. Mol. Cell. Endocrinol. 163:89-93.

Monget $\mathrm{P}$, Fabre $\mathrm{S}$, Mulsant $\mathrm{P}$, Lecerf $\mathrm{F}$, Elsen JM, Mazerbourg S, Pisselet C, Monniaux D. 2002. Regulation of ovarian folliculogenesis by IGF and BMP system in domestic animals. Domest. Anim. Endocrinol. 23: 139-154

Monget $\mathrm{P}$, Mazerbourg S, Delpuech T, Maurel MC, Maniere S, Zapf J, Gilles Lalmanach, Oxvig C, Overgaard MT. 2003. Pregnancy-Associated Plasma Protein-A Is Involved in Insulin-Like Growth Factor Binding Protein-2 (IGFBP-2) Proteolytic Degradation in Bovine and Porcine Preovulatory Follicles: Identification of Cleavage Site and Characterization of IGFBP-2 Degradation. Biol. Reprod. 68: 77-86.

Nicholas B, Scougall RK, Armstrong DG, Webb R. 2002. Changes in insulin-like growth factor binding protein (IGFBP) isoforms during bovine follicular development. Reproduction 124: 439-446

Ning Y, Schuller AG, Conover CA, Pintar JE. 2008. Insulin-like growth factor (IGF) binding protein-4 is both a positive and negative regulator of IGFactivity in vivo. Mol. Endocrinol. 22: 1213-1225.

Ortega $\mathrm{HH}$, Palomar MM, Acosta JC, Salvetti NR, Dallard BE, Lorente JA, Barbeito CG, Gimeno EJ. 2008. Insulin-like growth factor I in ovarian follicles and follicular fluid of cows with spontaneous and induced cystic ovarian disease. Res, in Vet. Sci. 84: 419-27.

Overgaard MT, Boldt HB, Laursen LS, Sottrup-Jensen L, Conover CA, Oxvig C. 2001. Pregnancy-associated plasma protein-A2 (PAPPA2), a novel insulin-like growth factor-binding protein-5 proteinase. J Biol. Chem. 276: 21849-21853.

Oxvig C. 2015. The role of PAPP-A in the IGF system: location, location, location. J. Cell. Commun. Signal. 9: 177-187.

Perks CM, Wathes DC. 1996. Expression of mRNAs for insulinlike growth factor binding proteins $-2,-3$ and -4 in the ovine ovary throughout the oestrous cycle. J. Endocrinol.151: 241-249

Peter AT. 2004. An update on cystic ovarian degeneration in cattle. Reprod. Dom. Anim. 39: 1-7.

Poretsky L, Cataldo NA, Rosenwaks Z, Giudice LC. 1999. The insulin-related ovarian regulatory system in health and disease. Endocr. Rev. 20: 535-582

Probo M, Comin A, Cairoli F, Faustini M, Kindahl H, De Amicis I, Veronesi MC. 2011. Selected metabolic and hormonal profiles during maintenance of spontaneous ovarian cysts in dairy cows. Reprod. Domest. Anim. 46:448-454

QinX,ByunD,LauKH,BaylinkDJ,MohanS. 2000. Evidencethatthe interaction between insulin-like growth factor (IGF)-II and IGF binding protein (IGFBP)-4 is essential for the action of the IGF-IIdependent IGFBP-4 protease. Arch. Biochem. Biophys. 379: 209-216

Rajaram S, Baylink DJ, Mohan S. 1997. Insulin-like growth factor-binding proteins in serum and other biological fluids: regulation and functions. Endocr. Rev. 18: 801831.

Rechler MM, Clemmons DR. 1998. Regulatory Actions of Insulin-like Growth Factorbinding Proteins. TEM 9: 5.

Rey F, Rodríguez FM, Salvetti NR, Palomar MM, Barbeito CG, Alfaro NS, Ortega HH. 2010. Insulin-like growth factorII and insulin-like growth factor-binding proteins in bovine cystic ovarian disease. J. Comp. Pathol. 142: 193-204.

Rivera GM, Fortune JE. 2001. Development of codominant follicles in cattle is associated with a follicle-stimulating hormone-dependent insulin-like growth factor binding protein-4 protease. Biol. Reprod. 65: 112-118.

Rivera GM, Fortune JE. 2003b. Proteolysis of insulin-like growth factor binding proteins -4 and -5 in bovine follicular fluid: implications for ovarian follicular selection and dominance. Endocrinology 144: 29772987.

Rodríguez FM, Salvetti NR, Panzani CG, Barbeito CG, Ortega $\mathrm{HH}$, Rey F. 2011. Influence of insulin-like growth factorbinding proteins- 2 and -3 in follicular cysts in bovine with cystic ovarian disease. Anim. Reprod. Sci. 128: 1-

Rodríguez FM, Salvetti NR, Colombero ML, Stangaferro ML, Barbeito CG, Ortega HH, Rey F. 2013. Interaction between IGF1 and IGFBPs in bovine cystic ovarian disease". Anim. Reprod. Sci.140: 14-25

Rodríguez FM, Colombero M, Amweg AN, Huber E, Gareis NC, Salvetti, NR, Ortega HH, Rey F. 2015. Involvement of PAPP-A and IGFR1 in cystic ovarian disease in cattle. Reprod. Domest. Anim. 50:659-68.

Salvetti NR, Stangaferro ML, Palomar MM, Alfaro NS, Rey F, Gimeno EJ, Ortega HH. 2010. Cell proliferation and survival mechanisms underlying the abnormal persistence of follicular cysts in bovines with cystic ovarian disease induced by ACTH. Anim. Reprod. Sci. 122: $98-110$

Samaras SE, Canning SF, Barber JA, Simmen FA, Hammond JM. 1996. Regulation of insulin-like growth factor I biosynthesis in porcine granulosa cells. Endocrinology 137: 4657-4664.

Sanchez R, Schuermann Y, Gagnon-Duval L, Baldassarre H, Murphy BD, Gevry N, Agellon LB, Bordignon V, Duggavathi R. 2014. Differential abundance of IGF1, bile acids, and the genes involved in their signaling in the dominant follicle microenvironment of lactating cows and nulliparous heifers. Theriogenology 81: 771779 .

Santiago C, Voge JL, Aad PY, Allen DT, Stein DR, Malayer JR, Spicer LJ. 2005. Pregnancyassociated plasma protein-A and insulin-like growth factor binding protein mRNAs in granulosa cells of dominant and subordinate follicles of preovulatory cattle. Domest. Anim. Endocrinol. 28: 46-63.

Silva JR, Figueiredo JR, van den Hurk R. 2009. Involvement of growth hormone $(\mathrm{GH})$ and insulin-like growth factor 
(IGF) system in ovarian folliculogenesis. Theriogenology 71: 1193-1208

Song RX, Barnes CJ, Zhang Z, Bao Y, Kumar R, Santen RJ. 2004. The role of Shc and insulin-like growth factor 1 receptor in mediating the translocation of estrogen receptor alpha to the plasma membrane. Proc Natl. Acad. Sci. U. S. A. 101: 2076-81.

Souza Lenz MI, Ramirez Benavidez GF, Uribe Velásquez LF. 2007. Papel del factor de crecimiento semejante a la insulina (IGF1) en la regulación de la función ovárica. Biosalud. 6: 149-159.

Spicer LJ, Alpizar E, Vernon RK. 1994. Insulin-like growth factor-I receptors in ovarian granulosa cells: effect of follicle size and hormones. Mol. Cell. Endocrinol. 102: 69-76

Spicer LJ, Hamilton TD, Keefer BE. 1996. Insulin-like growth factor I enhancement of steroidogenesis by bovine granulosa cells and thecal cells: dependence on de novo cholesterol synthesis. J. Endocrinol. 151: 365-373.

Spicer LJ, Chamberlain CS. 2000. Production of insulin-like growth factor-I by granulosa cells but not thecal cells is hormonally responsive in cattle. J. Anim. Sci. 78: 29192926.

Spicer L, Alvarez P, Prado TM, Morgan GL, Hamilton TD. 2000. Effects of intraovarian infusion of insulin-like growth factor-I on ovarian follicular function in cattle. Domest. Anim. Endocrinol. 18: 265-278.

Spicer LJ. 2004. Proteolytic degradation of insulin-like growth factor binding proteins by ovarian follicles: a control mechanism for selection of dominant follicles. Biol. Reprod. 70: 1223-1230.

Spicer L, Voge JL, Allen DT. 2004. Insulin-like growth factor-II stimulates steroidogenesis in cultured bovine thecal cells. Mol. Cell. Endocrinol. 227:1-7

Spicer LJ, Echternkamp SE. 1995. The ovarian insulin and insulin-like growth factor system with an emphasis on domestic animals. Domest. Anim. Endocrinol. 12: 223245 .

Stewart RE, Spicer LJ, Hamilton TD, Keefer BE, Dawson LJ, Morgan GL, Echternkamp SE. 1996. Levels of insulinlike growth factor (IGF) binding proteins, luteinizing hormone and IGF-I receptors, and steroids in dominant follicles during the first follicular wave in cattle exhibiting regular estrous cycles. Endocrinology 137: 2842-2850.

Sudo N, Shimizu T, Kawashima C, Kaneko E, Tetsuka M, Miyamoto A. 2007. Insulin-like growth factor-I (IGF-I) system during follicle development in the bovine ovary: relationship among IGF-I, type 1 IGF receptor (IGFR-1) and pregnancyassociated plasma protein-A (PAPP-A). Mol. Cell. Endocrinol. 264: 197-203.

Vanholder T, Opsomer G, de Kruif A. 2006. Aetiology and pathogenesis of cystic ovarian follicles in dairy cattle: a review. Reprod. Nutr. Dev. 46: 105-119.

Velazquez MA, Spicer LJ, Wathes DC. 2008. The role of endocrine insulin-like growth factor-I (IGF-I) in female bovine reproduction. Domest. Anim. Endocrinol. 35: 325-342.

Wathes DC, Taylor VJ, Cheng Z, Mann GE. 2003. Follicle growth, corpus luteum function and their effects on embryo development in postpartum dairy cows. Reprod. Suppl. 61: 219-237.

Webb R, Garnsworthy PC, Gong JG, Armstrong DG. 2004. Control of follicular growth: Local interactions and nutritional influences. J. Anim. Sci. 82: 63-74.

Williams CY, Harris TG, Battaglia DF, Viguie C, Karsch FJ. 2001. Endotoxin inhibits pituitary responsiveness to gonadotrophin-releasing hormone. Endocrinology 142: 1915-1922.

Yang WC, Yang LG, Riaz H, Tang KQ, Chen L, Li SJ. 2013. Effects in cattle of genetic variation within the IGF1R gene on the superovulation performance and pregnancy rates after embryo transfer. Anim. Reprod. Sci. 143:24-29.

Yuan W, Lucy MC, Smith MF. 1996. Messenger ribonucleic acid for insulin-like growth factors-I and -II, insulin-like growth factor-binding protein-2, gonadotropin receptors, and steroidogenic enzymes in porcine follicles. Biol. Reprod. 55:1045-1054.

Zulu VC, Sawamukai Y, Nakada K, Kida K, Moriyoshi M. 2002. Relationship among insulin-like growth factor-I, blood metabolites and postpartum ovarian function in dairy cows. J. Vet. Med. Sci. 64:879-885. 